\title{
WET DEPOSITION OF PERSISTENT ORGANIC POLLUTANTS TO THE GLOBAL OCEANS
}

Elena Jurado, Foday Jaward, Rainer Lohmann, Kevin C. Jones, Rafel Simó and Jordi Dachs

\section{SUPPLEMENTARY MATERIAL}

\section{ANNEX I:}

Annex 1 aims to obtain the gas-phase washout due to adsorption on the raindrop ( $\left.\mathrm{W}_{\mathrm{G} \_ \text {ads }}\right)$. The adsorption can be described using the water interface/gas partitioning coefficient, $\mathrm{K}_{\mathrm{ia}}$, ( $\left.\frac{\text { mass of SOC } / \mathrm{m}^{2} \text { of water }}{\text { mass of SOC } / \mathrm{m}^{3} \text { of air }}\right)$ as described in Simcik 2004 (1) and estimated from physicochemical parameters of the compounds (2):

$W_{G, A D S}=K_{i a} \frac{\text { Surface Area }}{\text { Volume }}$

For raindrop size distributions the following relationships for surface area and volume are needed (3):

Surface Area $=\int_{0}^{\infty} \mathrm{n}\left(\mathrm{d}_{\mathrm{R}}\right) \pi \mathrm{d}_{\mathrm{R}}^{2} \partial \mathrm{d}_{\mathrm{R}}$

Volume $=\int_{0}^{\infty} n\left(d_{R}\right) \frac{\pi}{6} d_{R}^{3} \partial d_{R}$

where $d_{R}(m m)$ is the diameter of the raindrop and $n\left(d_{R}\right)\left(\mathrm{mm}^{-1} \mathrm{~m}^{-3}\right)$ is the number of drops per unit volume of air and diameter interval.

The above expression becomes: 
$W_{G, A D S}=K_{i a} 6000 \frac{\int_{0}^{\infty} n\left(d_{R}\right) d_{R}^{2} \partial d_{R}}{\int_{0}^{\infty} n\left(d_{R}\right) d_{R}^{3} \partial d_{R}}$

On the other hand, the most common description of the size distribution of raindrops is the exponential law proposed by Marshall and Palmer (4):

$n\left(d_{R}\right)=N_{0} \exp \left(-\Lambda d_{R}\right)$, with $\mathrm{N}_{0}=8000 \mathrm{~m}^{-3} \mathrm{~mm}^{-1}$ and $\Lambda=4.1 \mathrm{p}_{0}^{-0.21}\left(\mathrm{~mm}^{-1}\right) \cdot \mathrm{p}_{0}$ is the precipitation rate $\left(\mathrm{mm} \mathrm{h}^{-1}\right)$.

Solving the two integrals, results:

$\mathrm{W}_{\mathrm{G}, \mathrm{ADS}}=\mathrm{K}_{\mathrm{ia}} \cdot 6000 \frac{2 \cdot \mathrm{N}_{0} \cdot \Lambda^{-3}}{6 \cdot \mathrm{N}_{0} \cdot \Lambda^{-4}}=2000 \cdot \mathrm{K}_{\mathrm{ia}} \cdot \Lambda=2000 \cdot \mathrm{K}_{\mathrm{ia}} \cdot\left(4.1 \mathrm{p}_{0}^{-0.21}\right)$

\section{ANNEX II:}



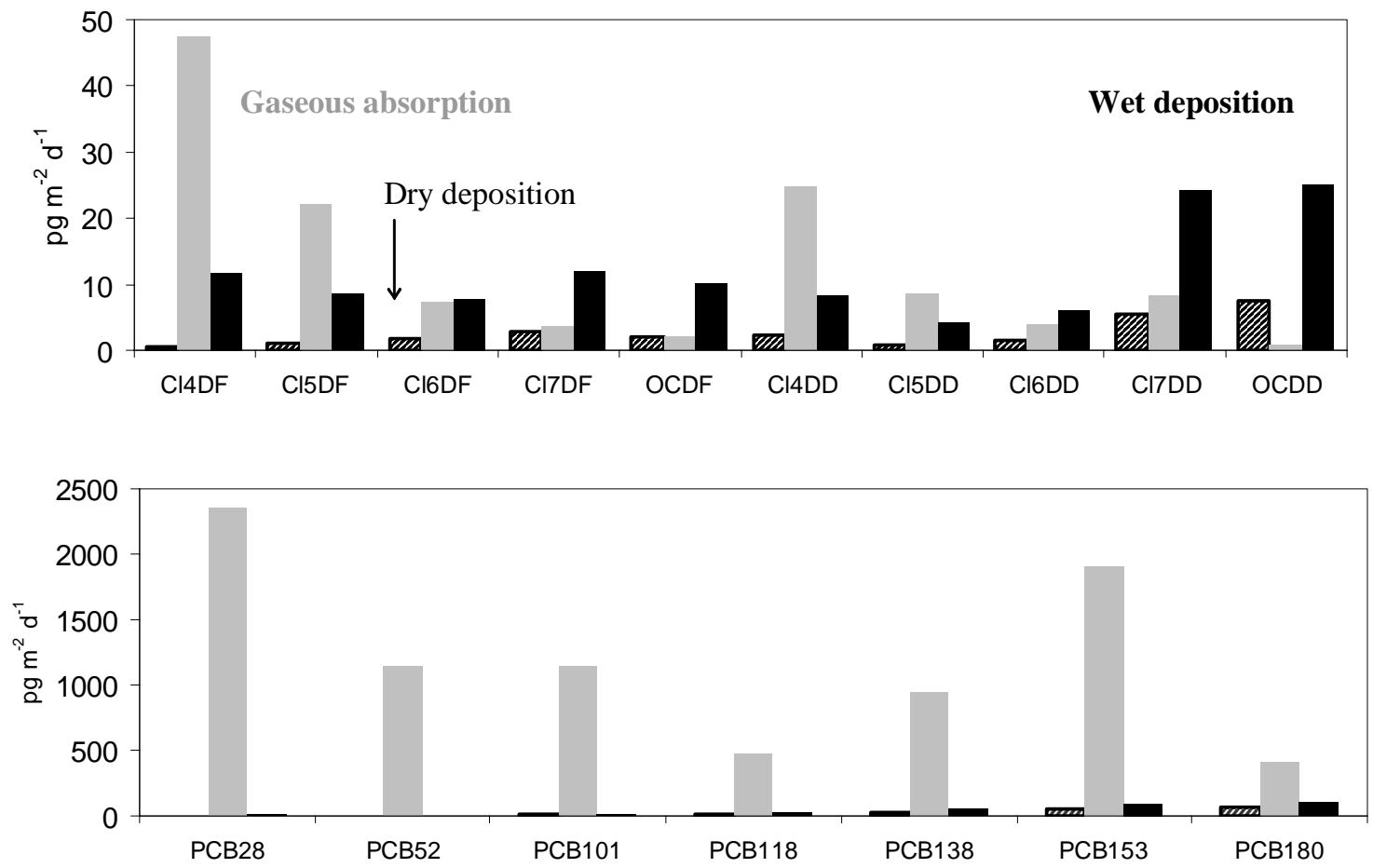

Figure II.1: Comparison of mean wet deposition, diffusive gaseous absorption to surface water and dry deposition fluxes for PCDD/Fs (A) and PCBs (B) to the Atlantic Ocean.

(1) Simcik, M. F. The importance of surface adsorption on the washout of semivolatile organic compounds by rain. Atmos. Environ. 2004, 38, 491-501.

(2) Roth, C. M.; Goss, K.-U.; Schwarzenbach, R. P. Adsorption of a Diverse Set of Organic Vapors on the Bulk Water Surface. J. Colloid Interface Sci. 2002, 252, 21-30.

(3) Seinfeld, J. H.; Pandis, S. N. Atmospheric chemistry and physics: From air pollution to climate change; Wiley-Interscience: New York, 1998.

(4) Marshall, J. S.; Palmer, W. M. The distribution of the raindrops with size. J. Meteorol. 1948, 5, 165-166. 